\title{
Peroxiredoxin 2: a potential biomarker for early diagnosis of Hepatitis B Virus related liver fibrosis identified by proteomic analysis of the plasma
}

\author{
Ye Lu ${ }^{1,2,3+}$, Jie Liü ${ }^{4+}$, Chengzhao Lin², Haijian Wang ${ }^{2}$, Ying Jiang ${ }^{5}$, Jiyao Wang ${ }^{4 *}$, Pengyuan Yang ${ }^{1,2^{*}}$, Fuchu He ${ }^{1,2,5^{*}}$
}

\begin{abstract}
Background: Liver fibrosis is a middle stage in the course of chronic Hepatitis B virus (HBV) infection, which will develop into cirrhosis and eventually hepatocellular carcinoma (HCC) if not treated at the early stage. Considering the limitations and patients' reluctance to undergo liver biopsy, a reliable, noninvasive diagnostic system to predict and assess treatment and prognosis of liver fibrosis is needed. The aim of this study was to identify biomarkers for early diagnosis of HBV related liver fibrosis.

Method: Plasma samples from 7 healthy volunteers and $27 \mathrm{HBV}$ infected patients with different stages of fibrosis were selected for 2-DIGE proteomic screening. One-way ANOVA analysis was used to assess differences in protein expression among all groups. The alteration was further confirmed by western blotting. Plasma levels of 25 serological variables in 42 healthy volunteers and 68 patients were measured to establish a decision tree for the detection of various stages fibrosis.

Result: The up-regulated proteins along with fibrosis progress included fibrinogen, collagen, macroglobulin, hemopexin, antitrypsin, prealbumin and thioredoxin peroxidase. The down-regulated proteins included haptoglobin, serotransferrin, CD5 antigen like protein, clusterin, apolipoprotein and leucine-rich alpha-2glycoprotein. For the discrimination of milder stage fibrosis, the area under curve for Prx II was the highest. Four variables (PT, Pre, HA and Prx II) were selected from the 25 variables to construct the decision tree. In a training group, the correct prediction percentage for normal control, milder fibrosis, significant fibrosis and early cirrhosis was $100 \%, 88.9 \%, 95.2 \%$ and $100 \%$, respectively, with an overall correct percent of $95.9 \%$.
\end{abstract}

Conclusion: This study showed that 2-D DIGE-based proteomic analysis of the plasma was helpful in screening for new plasma biomarkers for liver disease. The significant up-expression of Prx II could be used in the early diagnosis of HBV related liver fibrosis.

\section{Background}

Liver fibrosis is a middle stage in the course of chronic HBV infection, which will develop into cirrhosis and eventually hepatocellular carcinoma (HCC) if not treated at the early stage. The risk of developing cirrhosis depends on the degree of fibrosis (stage) and the degree of inflammation and necrosis (grade) in liver [1,2].

\footnotetext{
* Correspondence: jiyao_wang@hotmail.com; pyyang@fudan.edu.cn;

hefc@nic.bmi.ac.cn

† Contributed equally

'Department of Chemistry, Fudan University, Shanghai, China

${ }^{4}$ Department of Gastroenterology, Zhongshan Hospital, Fudan University,

Shanghai, China

Full list of author information is available at the end of the article
}

Although liver biopsy is currently recommended as the gold standard method of staging fibrosis in patients with chronic HBV, it has several disadvantages such as poor patient compliance, sampling error, limited usefulness for dynamic surveillance and follow-up. Considering these limitations and patients' reluctance to undergo a liver biopsy, there is a need for the development of novel noninvasive techniques to detect early liver damage. Several clinical studies have attempted to identify serological markers that rely on the measurement of substances participating in the generation of the liver extra cellular matrix. The current applications include hyaluronic acid (HA) [3,4], type IV collagen (CIV) [4], $\mathrm{N}$-terminal propeptide of type III procollagen 
(PIIIP) [3,5], metalloproteinases [6], inhibitors of metalloproteinases [6], and transforming growth factor beta [7]. Although some of these markers have shown promise for the detection of advanced fibrosis, their sensitivities for detecting milder fibrosis are generally poor. Therefore, a reliable, noninvasive diagnostic system to predict and assess treatment and prognosis of liver fibrosis is needed.

The biomarkers mentioned above have been identified through a candidate approach (i.e. derived from knowledge of basic biology and pathophysiology insights). With recent advances in genomics and proteomics, biomarkers can now be identified by discovery (or hypothesis generation) strategies that are not limited by our existing biological knowledge. By comprehensively examining different protein expression profiles between normal and pathological or drug treated samples, proteomics may provide information on new biomarkers, disease associated targets and the process of pathogenesis. This technique has been extensively employed to investigate cancers and other diseases [8-17].

$2-\mathrm{DE}$ is a powerful technique capable of resolving several thousand proteins based on their isoelectric points in the first dimension and their sizes in the second dimension [18]. A fundamental improvement was the development of 2-D fluorescent difference in-gel electrophoresis (DIGE) [19], which has the ability to analyze multiple protein samples within one gel. This is achieved through covalent modification of each protein with structurally similar but spectrally distinct fluorphores (CyDye2, CyDye3, and CyDye5). On each gel, two samples and an internal standard comprising an equal amount of each sample within the study can be examined. This process reduces the gel-to-gel variation and allows more accurate and sensitive proteomic quantization [20,21].

In the present study, we employed the DIGE technology to identify plasma profiles of liver fibrosis-related proteins, and the further confirmation with western blotting and ELISA showed that Prx II was better than the current available markers in detecting milder fibrosis. The present findings demonstrate that proteomics is a powerful approach for the molecular characterization of liver fibrosis progression and the identification of novel markers for the diagnosis of liver fibrosis.

\section{Methods}

\section{Human Samples}

Plasma samples of 49 healthy volunteers and 95 patients with chronic hepatitis B virus infection were collected between 2004 and 2005 from Zhongshan Hospital, Shanghai and State Key Laboratory of Proteomics, Beijing Proteome Research Center, Beijing, with the approval of the Ethical Committee at Fudan University. In screening study, subjects were restricted to patients having the same G3 grade inflammation (moderate piecemeal necrosis in portal with severe focal cell damage in lobule) to minimize unrelated variables and six groups (healthy, S1-S4 fibrosis and cirrhosis) were enrolled (Table 1). In validation study, four groups (healthy, milder fibrosis (S1), significant fibrosis (S2 and S3), early cirrhosis (S4)) were enrolled to facilitate data analysis (Table 2).

All patients were measured for $\mathrm{HBsAg}, \mathrm{HBeAg}$ and $\mathrm{HBcAg}$ for sure of anti-HBV positive. All patients were HBV-DNA positive (bDNA Assay 3.0, Bayer, Leverkusen). Patients with other hepatitis virus (HAV, HCV, HEV) infection, other liver diseases, HIV co-infections, and other malignomas or antiviral treatment were excluded. Liver biopsies were obtained from all patients. All samples ranged from 1.5 to $2.0 \mathrm{~cm}$ long, more than $1.0 \mathrm{~mm}$ thick and included at least 10 portal tracts. Classification of the fibrosis stages and inflammation grades was done according to Scheuer et al. [22]. The results of biopsy were interpreted by two pathologists independently.

\section{Preparation of plasma samples}

Blood samples were collected in sodium heparin coated plastic tubes for the preparation of plasma. After centrifuged at 4,000 g for $10 \mathrm{~min}$, the supernatant plasma were divided and stored in aliquots at $-80^{\circ} \mathrm{C}$ until analysis. Samples were thawed only once for the study. Before 2-DE, plasma was pretreated to deplete albumin and IgG with the ProteoExtract Albumin/IgG Removal Kit (Calbiochem, Darmstadt, Germany) and desalted with the ProteoExtract Protein Precipitation Kit (Calbiochem, Darmstadt, Germany). All experiments were done according to the manufacture's instruction. Samples were dissolved in $100 \mu \mathrm{L}$ of the DIGE lysis buffer (8 M Urea, $4 \% \mathrm{w} / \mathrm{v}$ CHAPS and $30 \mathrm{mM}$ Tris) and adjusted to $\mathrm{pH} 8.5$. Protein content was determined using the modified method of Bradford.

\section{DIGE Electrophoresis}

For screening study, samples in the same group were pooled to decrease the individual differences. The same group of sample was labeled with either CyDye 3 or CyDye 5 and ran in two different gels to eliminate the effect of dyes. $50 \mu \mathrm{g}$ protein of each group was labeled with $0.8 \mu \mathrm{L}$ of CyDye3 or CyDye5 DIGE fluors minimal dyes $(400 \mu \mathrm{M})$, respectively. After $30 \mathrm{~min}$, the incubation was stopped by adding $1 \mu \mathrm{L}$ of $10 \mathrm{mM}$ lysine. The labeled samples were further diluted with an equal volume of the $2 \times$ sample buffer containing $8 \mathrm{M}$ urea, 4\% w/v CHAPS, 2\% DTT, and 2\% Pharmalyte pH3-10. The internal standard included $8.33 \mu \mathrm{g}$ of each group (6 groups in total) labeled with CyDye2. Two different groups (CyDye3 and CyDye5) and the internal standard (CyDye2) were run per gel. The three labeled samples 
Table 1 Clinical features of all the subjects for screening study

\begin{tabular}{lcccccc}
\hline & Healthy & G3S1 & G3S2 & G3S3 & G3S4 & Cirrhosis \\
\hline Number & 7 & 5 & 5 & 5 & 7 & 5 \\
Age (Mean \pm SD) & $33.3 \pm 9.1$ & $35.8 \pm 12.0$ & $34.4 \pm 14.3$ & $34 \pm 10.4$ & $38.5 \pm 15.1$ & $43.3 \pm 10.1$ \\
Gender (Male/Female) & $7 / 0$ & $4 / 1$ & $4 / 1$ & $4 / 1$ & $6 / 1$ & $4 / 1$ \\
\hline
\end{tabular}

were mixed and the volume was adjusted to $350 \mu \mathrm{L}$ with rehydratation buffer containing $8 \mathrm{M}$ urea, $4 \% \mathrm{w} / \mathrm{v}$ CHAPS, $13 \mathrm{mM}$ DTT, and 1\% (v/v) IPG ampholytes $\mathrm{pH}$ 3-10. All gels, six in total, were processed and analyzed simultaneously. The first dimension was carried out on an IPGphor system (Amersham Biosciences) using pH310 IPG gel strips of $24 \mathrm{~cm}$. The IEF was performed at $20^{\circ} \mathrm{C}$ under the following conditions: $12 \mathrm{~h}$ at $50 \mathrm{~V} ; 30$ $\min$ at $250 \mathrm{~V} ; 30 \mathrm{~min}$ at $500 \mathrm{~V} ; 1 \mathrm{~h}$ at $1000 \mathrm{~V} ; 1 \mathrm{~h}$ at $2000 \mathrm{~V} ; 1 \mathrm{~h}$ at $4000 \mathrm{~V} ; 2 \mathrm{~h}$ at $8000 \mathrm{~V}$ and held at 8000 $\mathrm{V}$ until the total Vhr reached $80000 \mathrm{Vhr}$. After isoelectric focusing, the IPG strips were equilibrated for $10 \mathrm{~min}$ in a reduction buffer (6 M urea, 30\% (v/v) glycerol, $0.5 \% \mathrm{w} / \mathrm{v}$ DTT, and $2 \%(\mathrm{~m} / \mathrm{v})$ SDS in $0.05 \mathrm{M}$ Tris$\mathrm{HCl}$ buffer, pH8.8) and subsequently alkylated for 10 min in an alkylation buffer containing $6 \mathrm{M}$ urea, 30\% $(\mathrm{v} / \mathrm{v})$ glycerol, $4.5 \%(\mathrm{w} / \mathrm{v})$ iodoacetamide, and $2 \%(\mathrm{w} / \mathrm{v})$ SDS in $0.05 \mathrm{M}$ Tris- $\mathrm{HCl}$ buffer, $\mathrm{pH} 8.8$. The second dimensional separation was carried out on the custommade 12\% SDS-polyacrylamide gels and a Hoefer DALT electrophoresis system (Amersham Biosciences).

\section{Gel Image and Data Analysis}

The gels were scanned using the Typhoon 9410 laser scanner (Amersham Biosciences) at three different settings (CyDye2, blue laser $488 \mathrm{~nm}$ and $520 \mathrm{bp} 40$ filter; CyDye3, green laser $532 \mathrm{~nm}$ and 580 bp 30 filter; CyDye5, red laser $633 \mathrm{~nm}$ and $670 \mathrm{bp} 30$ filter). Three images per gel were obtained (18 in total). The scanned images were analyzed using DeCyder 6.5 (Amersham Biosciences). Spots were automatically detected and visually checked for undetected or incorrectly detected spots. The protein spots detected in each image were automatically linked among the three images per gel. All gels were matched to a digitized reference gel, containing all the protein spots present in all six internal standard images. The intensity levels per image were normalized by dividing the spot volume through the total intensity of all the spots in the image and multiplying it by the average of the total spot intensity of all 18-gel images. Subsequently, the CyDye3 and CyDye5 labeled spot volumes were divided by the spot volume of the corresponding protein spot in the internal standard (CyDye2) image. The differences in spot ratios were analyzed by one-way ANOVA analysis and the Student's $t$ test (assuming normal distributions and equal variance). One-way ANOVA was performed for the parameter of "liver fibrosis". The $P$ value cut-off for ANOVA was 0.05 . The proteins, found to be significant in the first step, were further analyzed with the $t$ test between each paired groups. The $P$ value cut-off for the $t$ test was 0.05 , and the fold change was 1.5 .

\section{In-gel Digestion and MALDI-TOF MS}

After scanning, the gel was stained by the MS accommodated silver staining method. For each gel spot, a biopsy punch was speared (Amersham Biosciences) and transferred to a $1.5 \mathrm{~mL}$ siliconikzed Eppendorf tube. Subsequently, the transferred gel spots were destained in a destaining solution $\left(100 \mathrm{mM} \mathrm{Na}_{2} \mathrm{~S}_{2} \mathrm{O}_{3}\right.$ and $30 \mathrm{mM} \mathrm{K}{ }_{3} \mathrm{Fe}$ $\left.(\mathrm{CN})_{6}, \mathrm{~V} / \mathrm{V}, 1: 1\right)$. The destained gel slices underwent prereduction using $100 \%$ acetonitrile (HPLC grade), and gel slices were dried in a Speed-Vac. After dried, gel slices were incubated at $37^{\circ} \mathrm{C}$ for $12-16 \mathrm{~h}$ in an $\mathrm{ABC}$ buffer (50 mM ammonium bicarbonate, pH8.0) containing $0.1 \mathrm{mg} / \mathrm{mL}$ sequencing grade modified trypsin (Promega Biosciences, San Luis Obispo, CA). Peptide samples were mixed at a ratio of $0.5 \mu \mathrm{L}$ matrix (R-cyano-4-hydroxytranscinnamic acid) and $0.5 \mu \mathrm{L}$ sample, loaded onto a $96 \times 2$ samples plate (Corning, P/N V700813), and crystallized. The crystallized samples were analyzed using an Applied Biosystems 4700 Proteomics Analyzer. In addition, trypsin-digested myglobin was used as an external standard for the mass calibration. PMF and sequence data were matched by searching the Swiss-Prot database using the MASCOT engine (Matrix Science).

\section{Western blot analysis}

For Western blot analysis, undepleted plasma proteins $(20 \mu \mathrm{g})$ were loaded onto each lane, size fractionated by

Table 2 Clinical features of all the subjects for validation study

\begin{tabular}{lcccc}
\hline & Healthy & Milder fibrosis & Significant fibrosis & Early Cirrhosis \\
\hline Number & 42 & 24 & 32 & 12 \\
Age (Mean \pm SD) & $32.9 \pm 9.2$ & $37.4 \pm 12.4$ & $34.4 \pm 11.7$ & $38.5 \pm 14.4$ \\
Gender (Male/Female) & $42 / 0$ & $22 / 2$ & $28 / 4$ & $10 / 2$ \\
\hline
\end{tabular}


SDS-PAGE, transferred to PVDF membrane (Amersham Pharmacia Biotech), and blocked with PBS/5\% skim milk/0.01\% Tween 20 for $30 \mathrm{~min}$ at room temperature. Primary polyclonal antibodies (Abcam) diluted according to the manufacture's instructions in a blocking buffer were added, with subsequent incubation for $1 \mathrm{~h}$ with horseradish peroxidase-conjugated secondary antibodies (Abcam). Samples were washed and developed with ECL-Plus (Amersham Pharmacia Biotech).

\section{Serological analysis}

The plasma levels of Prx II, CLU, HP, Apo AI, LN, CIV and PIIIP were detected by the double antibody sandwich ELISA assay according to the published method [23]. All antibodies used are from Abcom, Santa Cruz or Abnova. ELISA absorbance at $450 / 570 \mathrm{~nm}$ was measured to analyze the plasma protein levels semi-quantitatively. The plasma levels of HA were detected by RIA with the HA test kit, following the manufacture's instructions. Other clinical biochemical tests were done as a routine work in our laboratory on Hitachi 7600 Biochemistry Auto analyzer (Hitachi, Japan). Two independent researchers from our group performed all analyses blinded and in duplicate.

\section{Statistical Analysis}

The SPSS 13.0 (SPSS Inc., Chicago, IL) was used to perform all statistical comparisons. All comparisons were two-tailed, and a $P$ value $<0.05$ was considered significant. Independent sample $t$-tests were used to analyze protein plasma differences among the various groups. ROC curves and AUCs were calculated, with 95\% CIs. Classification tree was developed and the growing method is CHAID with a significant level of 0.05 for both splitting and merging.

\section{Results}

\section{Quantitative comparison and identification of protein spots on DIGE gels}

To smooth intrinsic individual differences and enhance common characteristic traits only related to disease status, plasma samples from individuals in the same group were pooled together for the analysis. The same group of sample was labeled with either CyDye3 or CyDye 5 and ran in two different gels (Additional file 1, Table S1). Dye swap images of each sample were acquired and analyzed to confirm the reproducible spot pattern with both dyes (Additional file 1, Figure S1). The 2-DE DIGE images of the samples of different groups labeled with different cyanine dyes were obtained by fluorescence scanning (Figure 1). The 2-D DIGE images were analyzed by DeCyder 5.0 to objectively estimate the abundance of proteins in each sample and to generate quantitative data. In total, 812 protein spots were auto- detected. Based on the threshold of $\mid$ ratio $\mid \geq 1.5$ and $P \leq$ 0.05 (one-way ANOVA), the software detected 30 protein spots that showed a significant change among various groups (Figure 1 and Table 3). Figure 2 and 3 showed the identification of Prx II and CLU, respectively. Identification of Prx II by MALDI-TOF MS/MS is shown in Additional file 2, Figure S2. The raw MS data may be downloaded from the ProteomeCommons. org Tranche network using the following hash: TIa/ TaABaUPU2yCPt/TxF8XDiKybQOSEqzWw76bpSSYwhmeMym9wDrfh+D4HYSudr1P319LQoH3RtcORcGfoaDvEh5wAAAAAAABCjQ==. The URL of this dataset is https://proteomecommons.org/dataset.jsp?i=TIa\%2FTaABaUPU2yCPt\%2FTxF8XDiKybQOSEqzWw76bpSSYwhmeMym9wDrfh\%2BD4HYSudr1P319LQoH3RtcORcG foaDvEh5wAAAAAAABCjQ\%3D\%3D, and of data download is https://proteomecommons.org/tranche/ data-downloader.jsp?h=TIa\%2FTaABaUPU2yCPt\% 2FTxF8XDiKybQOSEqzWw76bpSSYwhmeMym9wDrfh \%2BD4HYSudr1P319LQoH3RtcORcGfoaDvEh5wAA AAAAABCjQ\%3D\%3D.

\section{Western blot analysis for Prx II and CLU in plasma}

To confirm the differential expression of Prx II, western blotting analysis was also performed using polyclonal antibodies against Prx II (Figure 4A). Because of the huge diversity of protein concentration in plasma among individuals, we did not normalize the result of western blot with a house-keeping protein as usual. Instead, we analyzed the expression of CLU from the same lane of each sample to avoid errors in sample loading and membrane transferring. As expected, the changes of both proteins were similar to that of DIGE result (Figure 4B,C), Compared to normal plasma, Prx II showed to be highly present in all stage of fibrosis plasma, although the up-regulation of Prx II was withdrawn at S3 stage. The presence of CLU showed to decrease continuously with the progress of fibrosis. Thus, the up-expression of Prx II was reliable.

\section{Measurement of Plasma Levels of Prx II and HA}

We observed a significantly increased level of plasma Prx II among the milder fibrosis patients $(0.9033 \pm 0.2925$, $\mathrm{n}=24$ ) compared with that among the normal controls $(0.5176 \pm 0.1672, \mathrm{n}=42, P<0.01)$. The plasma level of Prx II in the significant fibrosis $(0.6681 \pm 0.2090, \mathrm{n}=32)$ and early cirrhosis $(0.8083 \pm 0.2081, \mathrm{n}=12)$ were reduced compared to that in the early stage, but still higher than the normal controls (Figure 5A). We observed a significantly elevated level of plasma HA among the early cirrhosis patients $($ median $=561.9317 \pm 183.0116, \mathrm{n}=12$ ) compared to normal controls (median $=91.7035 \pm$ 60.3199, $\mathrm{n}=38, P<0.01$ ), milder fibrosis patients $(125.8983 \pm 93.3860, \mathrm{n}=24, P<0.01)$ and significant 


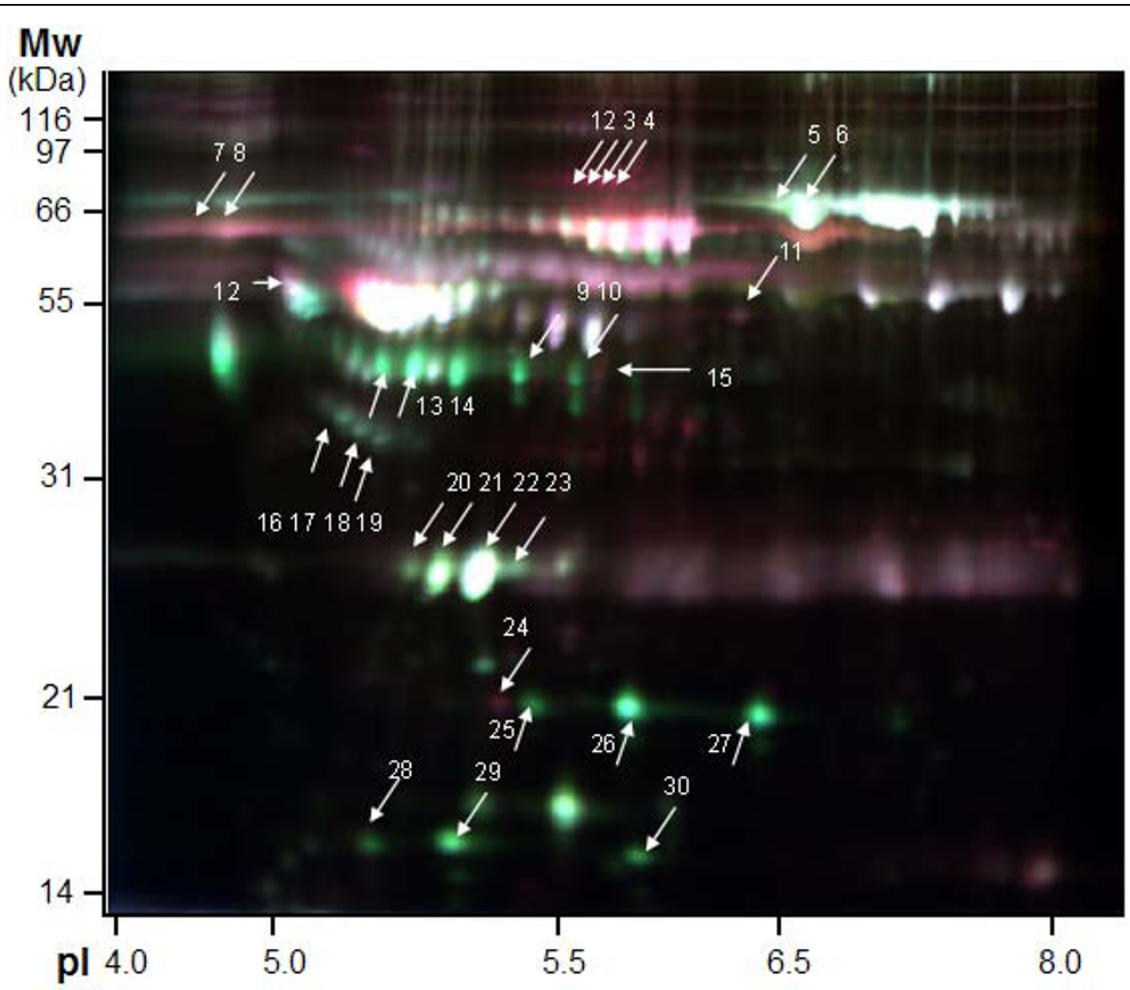

Figure 1 False-colored DIGE gel image of plasma proteins from normal and patient groups. Cy2 (blue) image of proteins from internal standard plasma; Cy3 (green) and Cy5 (red) image of proteins from plasma of different groups. The overlay images showed white spots containing proteins that have equal expression levels in each two group samples, red spots containing proteins with a higher expression and green spots containing proteins with a lower expression in the progressive phase of fibrosis. Spots for which the volume |ratio $\geq 1.5$ ( $t$ test) and $P \leq 0.05$ (oneway ANOVA) based on DeCyder software analysis were identified by MS. In some cases, different spots were identified as the same protein.

fibrosis patients $(150.6675 \pm 108.6073, \mathrm{n}=32, P<0.01)$ (Figure 5B).

\section{Clinical diagnosis of $\mathbf{2 5}$ serological analysis markers}

Twenty-five serological analysis markers, including 4 differential proteins found by 2D-DIGE, 4 clinical plasma fibrosis markers and 17 serological biochemical markers were screened for their diagnosis values to various stages of fibrosis. Table 4 shows the areas under curves (AUCs) of discriminatory values of receiver operating characteristic (ROC) analysis of 25 serological markers to normal, milder fibrosis, significant fibrosis and early cirrhosis. For the discrimination of milder fibrosis, the area under curve (AUC) of Prx II was the largest $(0.872 \pm 0.090$, Mean \pm SD), higher than other 24 markers $(0.148 \pm$ $0.076 \sim 0.733 \pm 0.098$, Mean $\pm \mathrm{SD}$ ). For significant fibrosis, the AUC of CIV was the largest $(0.799 \pm 0.013)$, higher than other 24 markers $(0.237 \pm 0.076 \sim 0.750 \pm 0.098$, Mean \pm SD). For early cirrhosis, the AUC of HA was the largest $(1.000 \pm 0.013)$, higher than other 24 markers $(0.100 \pm 0.076 \sim 0.907 \pm 0.098$, Mean \pm SD $)$. An AUC over 0.5 means the marker can be used for clinical diagnosis. The higher the AUC is, the more useful the marker may be. Unlike HA and CIV, which were useful for significant fibrosis and early stage cirrhosis diagnostician, Prx II was more efficient to milder fibrosis diagnostician.

For differentiation between various grades fibrosis, four variables (PT, Pre, HA and Prx II) were selected by SPSS software from the 25 variables to construct a decision tree (Figure 6). In a training group, 73 samples were first divided into three groups by marker "PT" (cutoff value = $12.00,13.60$ and 14.70 , respectively): normal $(25 / 25) \&$ milder fibrosis (10/18), milder (6/18) \& significant fibrosis $(11 / 21)$, significant fibrosis $(10 / 21)$ \& early cirrhosis (9/9). The normal \& milder fibrosis group was then correctly classified by marker "Pre" (cutoff value $=0.23$ ); the milder \& significant fibrosis group was then correctly classified by marker "Prx II" (cutoff value = 0.80); the significant fibrosis \& early cirrhosis group was then classified by marker "HA" (cutoff value $=381.74$ ) and all the early cirrhosis samples (9/9) were correctly classified. The correct prediction percentage of the algorithm for normal control, milder fibrosis, significant fibrosis and early cirrhosis was $100 \%, 88.9 \%, 95.2 \%$ and $100 \%$, respectively. The algorithm was further validated by a test group of 37 samples, and the correct prediction percentage for normal control, milder fibrosis, significant fibrosis and early cirrhosis was $100 \%, 100.0 \%, 88.9 \%$ and $100 \%$, respectively (Table 5). 
Table 3 List of identified proteins ${ }^{a}$

\begin{tabular}{|c|c|c|c|c|c|c|c|c|c|c|c|}
\hline $\begin{array}{l}\text { Spot } \\
\text { No. }{ }^{\text {) }}\end{array}$ & Protein ID $^{c)}$ & $\begin{array}{l}\text { Procession } \\
\text { No. }{ }^{d)}\end{array}$ & $\begin{array}{l}\text { Protein } \\
\text { Score }\end{array}$ & C.I. $\%^{\text {f) }}$ & $\begin{array}{c}\text { lon } \\
\text { Score }^{\mathrm{e})}\end{array}$ & C.I.\% ${ }^{\text {f) }}$ & Peptide & $\begin{array}{c}\mathrm{MW}(\mathrm{kDa})^{\mathrm{g})} \\
\text { theoretical/ } \\
\text { observed }\end{array}$ & $\begin{array}{c}\mathrm{pl}^{\mathrm{g})} \\
\text { theoretical/ } \\
\text { observed }\end{array}$ & Appearance $^{\text {h) }}$ & $\begin{array}{c}P \\
\text { value }^{\text {l) }}\end{array}$ \\
\hline 1 & $\begin{array}{c}\alpha-2 \\
\text { macroglobulin }\end{array}$ & P01023 & 341 & 100 & 185 & 100 & 34 & $163 / 90$ & $6 / 5.6$ & $12(18)$ & 0.03 \\
\hline 2 & $\begin{array}{c}\alpha-2 \\
\text { macroglobulin }\end{array}$ & P01023 & 341 & 100 & 185 & 100 & 34 & $163 / 90$ & $6 / 5.7$ & $12(18)$ & 0.03 \\
\hline 3 & $\begin{array}{c}\alpha-2 \\
\text { macroglobulin }\end{array}$ & P01023 & 341 & 100 & 185 & 100 & 34 & $163 / 90$ & $6 / 5.8$ & $12(18)$ & 0.03 \\
\hline 4 & $\begin{array}{c}\alpha-2 \\
\text { macroglobulin }\end{array}$ & P01023 & 341 & 100 & 185 & 100 & 34 & $163 / 90$ & $6 / 5.9$ & $12(18)$ & 0.03 \\
\hline 5 & Serotransferrin & P02787 & 297 & 100 & 119 & 100 & 33 & $77 / 80$ & $6.81 / 6.5$ & $15(18)$ & 0.012 \\
\hline 6 & Serotransferrin & P02787 & 78 & 99.992 & 37 & 99.6 & 13 & $77 / 80$ & $6.81 / 6.5$ & $12(18)$ & 0.015 \\
\hline 7 & Hemopexin & P02790 & 120 & 100 & 44 & 99.996 & 19 & $52 / 60$ & $6.55 / 4.5$ & $15(18)$ & 0.021 \\
\hline 8 & Hemopexin & P02790 & 178 & 100 & 80 & 100 & 19 & $52 / 60$ & $6.55 / 4.5$ & $15(18)$ & 0.025 \\
\hline 9 & LRG & P02750 & 108 & 100 & 55 & 100 & 15 & $34 / 34$ & $5.66 / 5.4$ & 18(18) & 0.029 \\
\hline 10 & LRG & P02750 & 199 & 100 & 134 & 100 & 18 & $34 / 34$ & $5.66 / 5.4$ & 18(18) & 0.041 \\
\hline 11 & $\begin{array}{l}\text { Fibrogen } \gamma \\
\text { chain }\end{array}$ & P02679 & 146 & 100 & 40 & 99.987 & 18 & $50 / 50$ & $5.61 / 5.9$ & $15(18)$ & 0.03 \\
\hline 12 & $\alpha-1$ antitrypsin & P01009 & 76 & 99.986 & 33 & 99.942 & 11 & $47 / 56$ & $5.37 / 5.2$ & $12(18)$ & 0.011 \\
\hline 13 & APO-AIV & P06727 & 143 & 100 & 41 & 99.991 & 15 & $45 / 45$ & $5.28 / 5.2$ & 18(18) & 0.021 \\
\hline 14 & APO-AIV & P06727 & 143 & 100 & 41 & 99.991 & 15 & $45 / 45$ & $5.28 / 5.2$ & 18(18) & 0.021 \\
\hline 15 & $\begin{array}{l}\text { Fibrogen } \beta \\
\quad \text { chain }\end{array}$ & P02675 & 341 & 100 & 150 & 100 & 36 & $56 / 46$ & $8.54 / 5.5$ & 15(18) & 0.021 \\
\hline 16 & Clusterin & P10909 & 144 & 100 & 86 & 100 & 17 & $52 / 40$ & $5.89 / 5.0$ & 18(18) & 0.013 \\
\hline 17 & Clusterin & P10909 & 130 & 100 & 71 & 100 & 17 & $52 / 39$ & $5.89 / 5.2$ & 18(18) & 0.013 \\
\hline 18 & Clusterin & P10909 & 74 & 99.98 & 59 & 100 & 12 & $52 / 35$ & $5.89 / 5.3$ & $18(18)$ & 0.013 \\
\hline 19 & Clusterin & P10909 & 127 & 100 & 74 & 100 & 17 & $52 / 34$ & $5.89 / 5.4$ & 18(18) & 0.016 \\
\hline 20 & APO-A1 & P02647 & 255 & 100 & 87 & 100 & 28 & $31 / 28$ & $5.56 / 5.2$ & $18(18)$ & 0.013 \\
\hline 21 & APO-A1 & P02647 & 364 & 100 & 107 & 100 & 33 & $31 / 28$ & $5.56 / 5.3$ & 18(18) & 0.013 \\
\hline 22 & APO-A1 & P02647 & 214 & 100 & 21 & 99.305 & 25 & $31 / 28$ & $5.56 / 5.3$ & $18(18)$ & 0.021 \\
\hline 23 & APO-A1 & P02647 & 404 & 100 & 113 & 100 & 39 & $31 / 28$ & $5.56 / 5.4$ & $18(18)$ & 0.021 \\
\hline 24 & $\begin{array}{l}\text { Thioredoxin } \\
\text { peroxidase } 1\end{array}$ & P32119 & 263 & 100 & 143 & 100 & 16 & $22 / 21$ & $5.66 / 5.4$ & $15(18)$ & 0.021 \\
\hline 25 & $\mathrm{HP}-2$ & P00738 & 71 & 99.961 & 19 & 99.13 & 10 & $45 / 20$ & $6.13 / 5.4$ & 18(18) & 0.0031 \\
\hline 26 & $\mathrm{HP}-2$ & P00737 & 91 & 100 & 58 & 100 & 12 & $38 / 20$ & $6.13 / 5.6$ & 18(18) & 0.0051 \\
\hline 27 & $\mathrm{HP}-2$ & P00738 & 88 & 100 & 58 & 100 & 11 & $45 / 20$ & $6.13 / 6.3$ & 18(18) & 0.0051 \\
\hline 28 & Prealbulmn & P02766 & 53 & 97.616 & 25 & 99.732 & 7 & $16 / 16$ & $5.52 / 5.2$ & 18(18) & 0.0067 \\
\hline 29 & Prealbulmn & P02766 & 56 & 98.66 & 54 & 99.944 & 7 & $16 / 16$ & $5.52 / 5.3$ & 15(18) & 0.0067 \\
\hline 30 & Prealbulmn & P02766 & 127 & 100 & 64 & 100 & 10 & $16 / 16$ & $5.52 / 5.6$ & $12(18)$ & 0.013 \\
\hline
\end{tabular}

a) Spots for which the volume $\mid$ ratio| $\geq 1.5$ (t test) and $P \leq 0.05$ (one-way ANOVA) based on DeCyder software analysis were identified by MALDI-TOF/TOF MS.

b) Spots referring to Figure 2 .

c) Spots in the same line were identified as same protein.

d) Protein ID accessed from Swiss-Prot database by data searching.

e) Total protein score analyzed by MS and total ion score of the peptide analyzed by MS/MS.

f) Confidence of protein score and ion score.

g) Theoretical MW and pl accessed from UniProt database.

\section{Discussion}

Plasma proteins are quite reflective of the overall profile in humans. It is estimated that as many as 10,000 proteins are present within human plasma, many of which are secreted or shed by cells during different physiology or pathology processes [24]. Moreover, instead of tissue, the utility of plasma to classify the disease state would have great advantages in that the plasma is easy to collect, the procedure is minimally invasive, and samples can be collected repeatedly. Therefore, considerable efforts have been made to discover plasma biomarkers for clinical purposes $[25,26]$.

Recently, proteomics, a powerful strategy which can provide the global information of new biomarkers, 


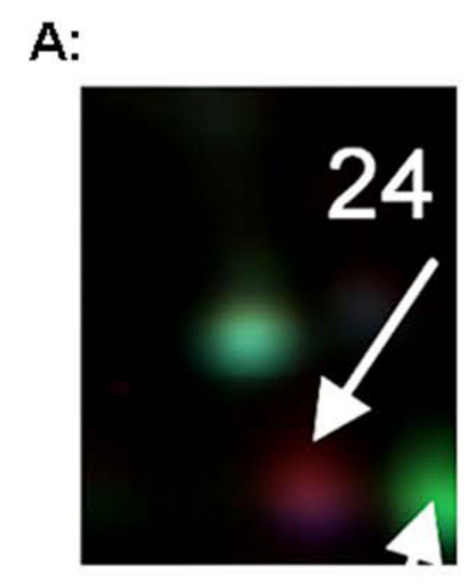

B:

$$
\text { C: }
$$

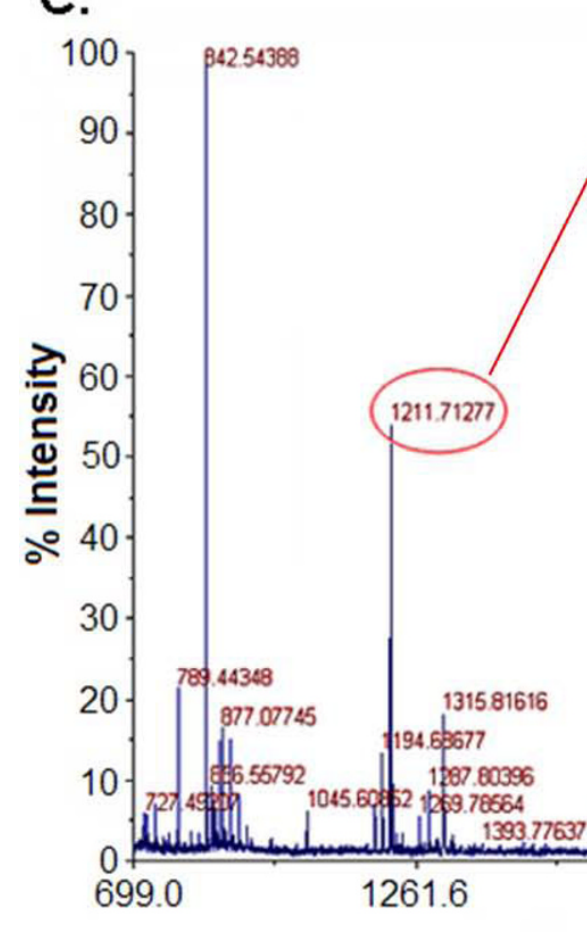

D:
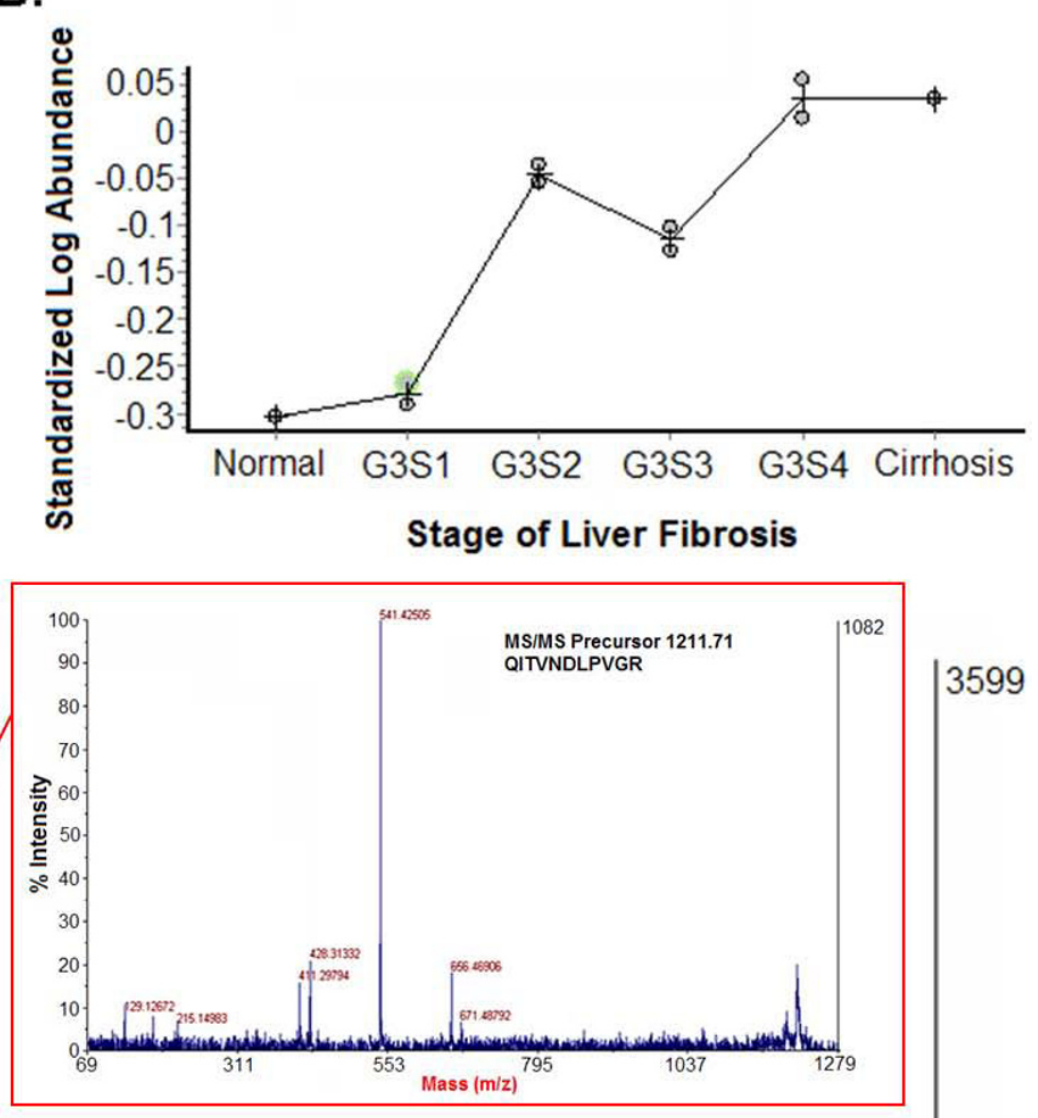

3599

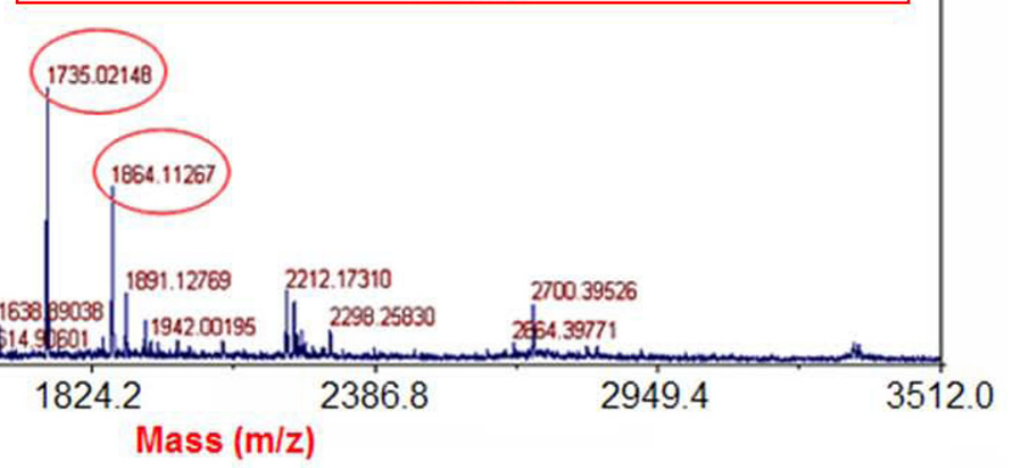

\section{MASGNARIGK PAPDFKATAV VDGAFKEVKL SDYKGKYVVL FFYPLDFTFV \\ 51 CPTEIIAFSN RAEDFRKLGC EVLGVSVDSQ FTHLAWINTP RKEGGLGPLN 101 IPLLADVTRR LSEDYGVLKT DEGIAYRGLF IIDGKGVLRQ ITVNDLPVGR 151 SVDEALRLVQ AFQYTDEHGE VCPAGWKPGS DTIKPNVDDS KEYFSKHN}

Figure 2 Plasma Prx II levels were up-regulated with fibrosis progress. A: Magnified region of DIGE gel image of Prx II. B: The patterns of the relative abundance alterations of Prx II in different groups. C: The MALDI-TOF MS map of Prx II, in which peptide peaks for further MS/MS identification are labeled out with mass value and the MS/MS map of peptide 1121.71 was shown. D: The amino acid sequences of Prx II, in which MS/MS matched peptide sequences, are underlined. 


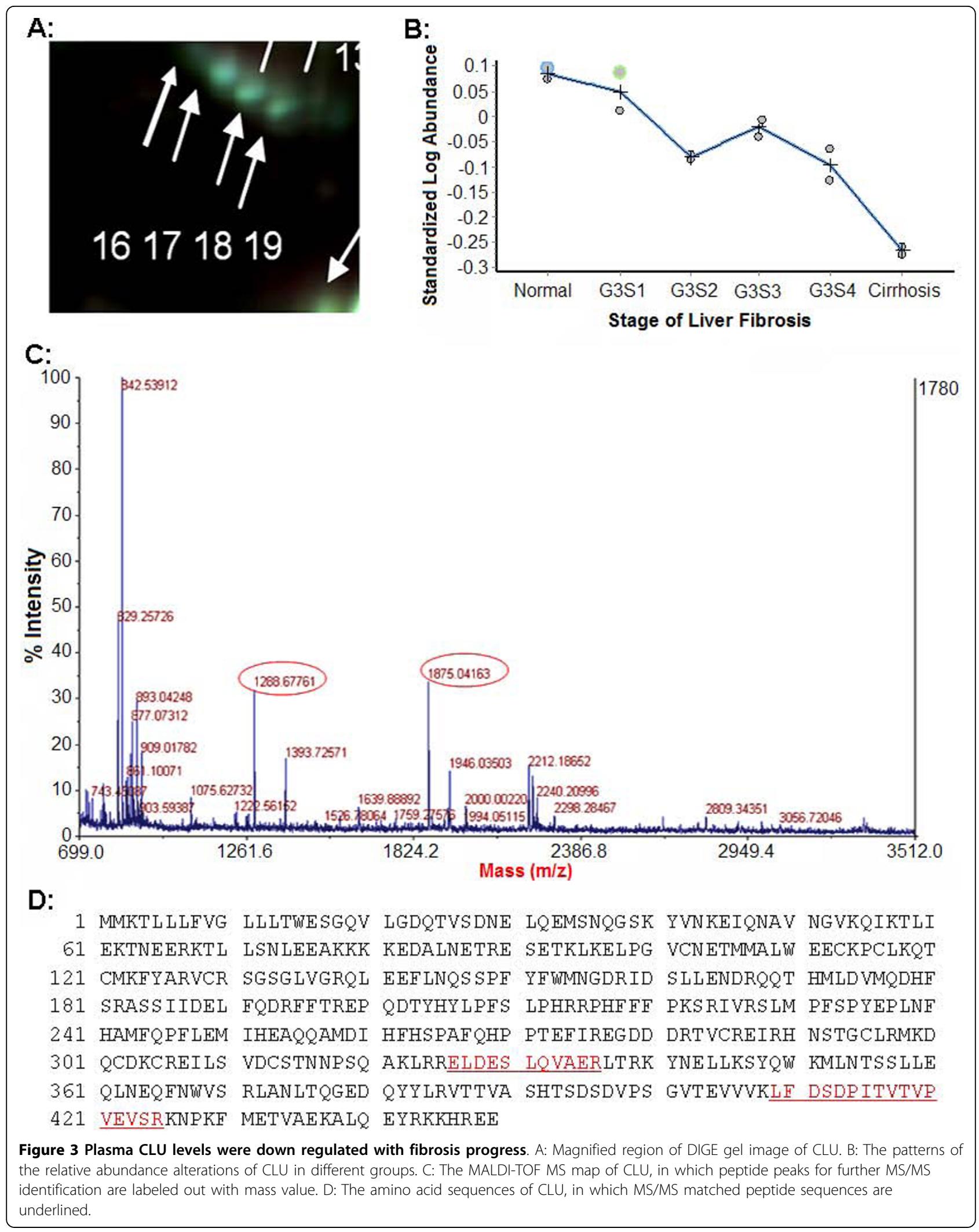



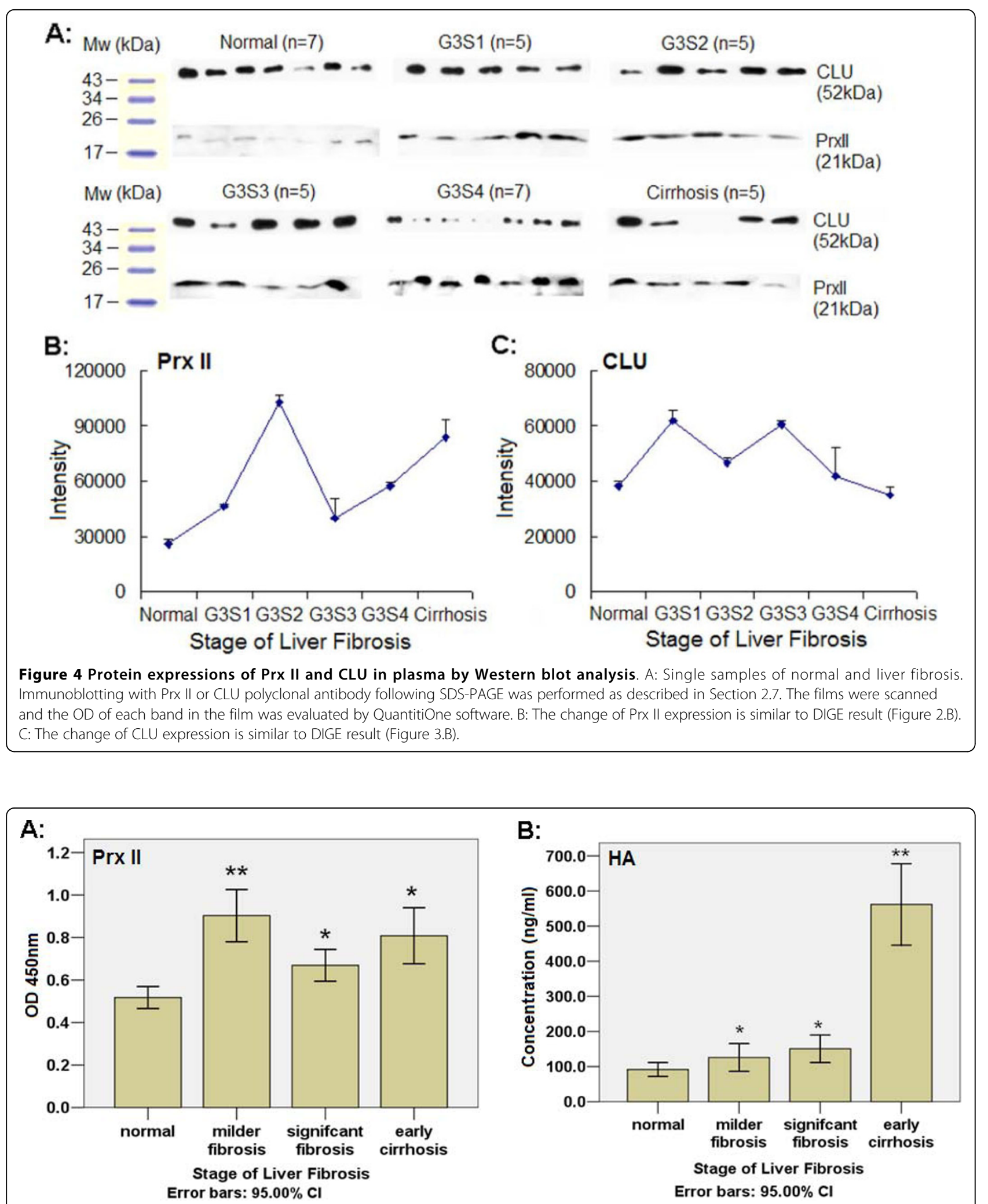

Figure 5 Human plasma levels of Prx II and HA. A: the plasma levels of Prx II were significantly elevated in patients with milder grade fibrosis compared to those in normal controls. The plasma level of Prx II in the late stage fibrosis and early cirrhosis were reduced compared to that in the early stage, but still higher than the normal controls. B: a significantly elevated HA plasma level among the early cirrhosis patients compared to normal controls and fibrosis patients. Compared to normal:* $P<0.05$, ${ }^{* *} P<0.01$. 
Table 4 Areas under curve of ROC analysis of 25 serological markers

\begin{tabular}{|c|c|c|c|c|}
\hline \multirow[b]{2}{*}{$\begin{array}{c}\text { Test } \\
\text { Variable }^{\text {a) }}\end{array}$} & \multicolumn{4}{|c|}{ State Variable ${ }^{\text {b) }}$} \\
\hline & Normal & $\begin{array}{l}\text { Milder } \\
\text { fibrosis }\end{array}$ & $\begin{array}{c}\text { Significant } \\
\text { fibrosis }\end{array}$ & $\begin{array}{l}\text { Early } \\
\text { cirrhosis }\end{array}$ \\
\hline A & 0.852 & 0.433 & 0.237 & 0.263 \\
\hline$A / G$ & 0.898 & 0.398 & 0.244 & 0.171 \\
\hline AFP & 0.356 & 0.338 & 0.666 & 0.857 \\
\hline AKP & 0.325 & 0.552 & 0.522 & 0.876 \\
\hline Apo Al & 0.508 & 0.423 & 0.565 & 0.468 \\
\hline AST/ALT & 0.818 & 0.148 & 0.247 & 0.692 \\
\hline$C B$ & 0.282 & 0.546 & 0.569 & 0.896 \\
\hline $\mathrm{CHE}$ & 0.695 & 0.441 & 0.468 & 0.100 \\
\hline C-IV & 0.136 & 0.470 & 0.799 & 0.894 \\
\hline CLU & 0.290 & 0.527 & 0.738 & 0.453 \\
\hline G & 0.119 & 0.610 & 0.713 & 0.878 \\
\hline $\mathrm{HA}$ & 0.314 & 0.478 & 0.549 & 1.0000 \\
\hline $\mathrm{HB}$ & 0.613 & 0.452 & 0.404 & 0.511 \\
\hline $\mathrm{HP}$ & 0.329 & 0.601 & 0.603 & 0.537 \\
\hline LN & 0.419 & 0.534 & 0.589 & 0.438 \\
\hline Prx $\|$ & 0.216 & 0.872 & 0.500 & 0.577 \\
\hline PIIIP & 0.475 & 0.512 & 0.498 & 0.558 \\
\hline PLT & 0.512 & 0.426 & 0.372 & 0.226 \\
\hline Pre & 0.543 & 0.506 & 0.568 & 0.263 \\
\hline PT & 0.098 & 0.242 & 0.528 & 0.855 \\
\hline rGT & 0.266 & 0.733 & 0.640 & 0.872 \\
\hline TB & 0.3750 & 0.587 & 0.551 & 0.907 \\
\hline $\mathrm{TC}$ & 0.688 & 0.424 & 0.294 & 0.637 \\
\hline $\mathrm{TG}$ & 0.541 & 0.454 & 0.502 & 0.466 \\
\hline WBC & 0.265 & 0.549 & 0.750 & 0.488 \\
\hline
\end{tabular}

a) Abbreviations used for test variables

A: albumin; A/G: albumin/lgG; AFP: alpha fetal protein; AKP: alkaline phosphotase; AST: Aspartate aminotransferase; ALT: Alanine Aminotransferase; CB: Combined bilirubin; CHE: cholinesterase; C-IV: collagen type IV; CLU: clusterin; G: IgG; HA: Sodium Hyaluronate; HB: hemoglobin; HP: Haptoglobin; LN: laminin; Prx II: thioredoxin peroxidase 2; PIIIP: pre-collagen peptide type III; PLT: platelets; Pre: prealbumin; PT: prothrombin time; rGT: gama glutamyl transpeptidase; TB: total bilirubin; TC: total cholesterol; WBC: white blood cells. b) The maximal AUCs for each state are shown in bold.

disease associated targets and the process of pathogenesis by comprehensively examining different protein expression profiles between normal and pathological or drug treated samples, has been extensively employed to investigate cancers and other diseases. However, plasma proteome analysis is still a daunting task largely due to abundant proteins such as albumin and IgG that constitute approximately $60-97 \%$ of the total plasma proteins [27]. Efficient depletion of abundant proteins from human plasma enables the detection of more proteins with greater protein coverage [28]. On the other hand, the depletion of highly abundant proteins may result in the loss of potentially important proteins bound to them at the same time. The more kinds of abundant proteins are depleted, the more unspecific bounded proteins may loose [29]. Therefore, we chose to deplete albumin and IgG to minimize the unspecific protein depletion (Additional file 3, Figure S3). Depleting these two abundant proteins prior to the DIGE technology increased the loading volume from $5 \mu \mathrm{L}$ to $35 \mu \mathrm{L}$ (estimated raw plasma volumes with same protein amount), and significantly improved the detection of low abundant proteins. Proteins, such as clusterin, hemopexin and thioredoxin peroxidase, could be detected in the $\mu \mathrm{g} / \mathrm{mL}$ range, which cannot be detected by the traditional 2-DE technology.

Pooling samples is a common way to reduce the cost of experiments as well as to provide equivalent power of experiments [30-32]. Since the purpose of our study is to identify robust biomarkers related with the progress of liver fibrosis, the differences among various groups are more interesting than the differences between patients within each patient group. We pooled the samples to smooth intrinsic individual differences and enhance common characteristic traits only related to disease status. It is also true that pooling samples may eliminate the number of biological replicates. Therefore, we analyzed protein levels in a larger population by ELISA to make up the disadvantages of pooling samples.

In this study, the albumin and IgG depletion strategy prior to 2-D DIGE was applied to enrich the lowabundant proteins in human plasma. By the 2-D DIGE, several proteins with significant alterations related with fibrosis progress were found. The up-regulated proteins were identified as fibrogen, collagen, macroglobulin, hemopexin, antitrypsin, prealbumin and thioredoxin peroxidase. The down-regulated proteins were haptoglobin, serotransferrin, CD5 antigen like protein, clusterin, apolipoprotein and leucine-rich alpha-2-glycoprotein (LRG). The biological functions of these proteins can be summarized into four groups: (A) Generation and degradation of extra cellular matrix (ECM), such as fibrogen, collagen and macroglobulin [33]; (B) Acute phase reaction and immunity protection, such as antitrypsin, prealbumin, LRG [34] and CD5 antigen-like protein; (C) Oxygenation and cell apoptosis, such as clusterin [35] and thioredoxin peroxidase [36,37]; (D) Transport and metabolism, such as apolipoprotein, haptoglobin, hemopexin and serotransferrin. As expected, proteins related to the generation of extra cellular matrix had the same alteration pattern of increase, which is in accordance with the progress of fibrosis. Proteins with the function of transport and metabolism had the same alteration pattern of decrease, which implied the dysfunction of the liver with the development of fibrosis. Most of the proteins found to be upor down regulated were described in prior papers, which imply the reliability of our study design and the DIGE technology. 


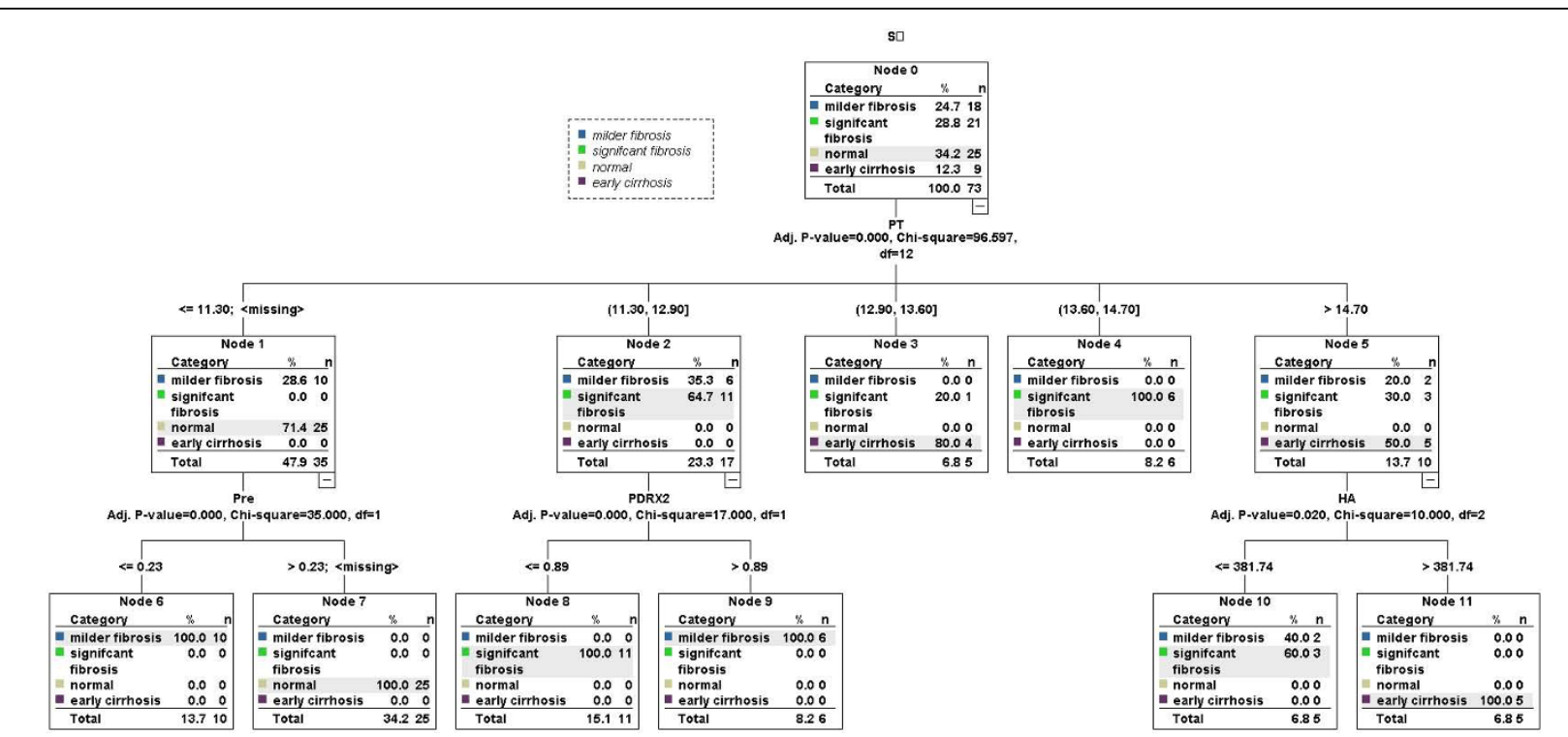

Figure 6 Decision tree for the differentiation of various stages fibrosis using four serological markers. Briefly, in a training group of 73 samples, samples were first divided into three groups (normal \& milder fibrosis, milder \& significant fibrosis, significant fibrosis \& early cirrhosis) by marker "PT" (cutoff value $=12.00,13.60$ and 14.70, respectively); The normal \& milder fibrosis group was then correctly classified by marker "Pre" (cutoff value = 0.23); the milder \& significant fibrosis group was then correctly classified by marker "Prx II" (cutoff value $=0.80$ ); the significant fibrosis \& early cirrhosis group was then classified by marker "HA" (cutoff value $=381.74$ ) and all the early cirrhosis samples $(9 / 9)$ were correctly classified. The correct prediction percentage of the algorithm for normal control, milder fibrosis, significant fibrosis and early cirrhosis was $100 \%, 88.9 \%, 95.2 \%$ and $100 \%$, respectively.

However, some of the identified proteins had different observed MW or pI, compared to theoretical ones. This is because that the proteins detected in plasma are secreted proteins, which are usually smaller than the whole protein. And the post translation modification of proteins, either carbamidomethyl, oxidation or phosphorylation, will change the $\mathrm{pI}$ of proteins greatly.

Of the 13 identified proteins, thioredoxin peroxidase appears to be a novel candidate as useful HBV-related milder grade liver fibrosis marker. Large evidence shows that in humans and animals, oxidative stress is implicated in the resistance to HBV infection and serves as a link between hepatic injury and fibrosis [38,39]. Thioredoxin peroxidases, also called peroxiredoxins, are members of a newly discovered family of peroxidases, and they efficiently reduced the intracellular level of $\mathrm{H}_{2} \mathrm{O}_{2}$ produced in those cells stimulated by various cell surface ligands. The peroxiredoxin family was reported to be closely related to various causes of liver fibrosis. They were found to be up-regulated in liver fibrosis caused by alcohol exposition [40], schistosomiasis [41], drug and chemical induction $[41,42]$. The oxidation kinetics of all peroxiredoxins was extremely rapid and sensitive, occurring at $\mathrm{H}_{2} \mathrm{O}_{2}$ doses unable to affect common markers of

Table 5 Correct percentage of prediction for various grades fibrosis

\begin{tabular}{|c|c|c|c|c|c|c|}
\hline & & \multicolumn{5}{|c|}{ Predicted } \\
\hline \multicolumn{2}{|c|}{ Sample Observed } & normal & $\begin{array}{c}\text { Milder } \\
\text { fibrosis }\end{array}$ & Significant & $\begin{array}{c}\text { Early } \\
\text { cirrhosis }\end{array}$ & $\begin{array}{c}\text { Percent } \\
\text { Correct (\%) }\end{array}$ \\
\hline \multirow[t]{5}{*}{ Training } & normal & 25 & 0 & 0 & 0 & 100 \\
\hline & milder fibrosis & 0 & 16 & 2 & 0 & 88.9 \\
\hline & significant fibrosis & 0 & 0 & 20 & 1 & 95.2 \\
\hline & early cirrhosis & 0 & 0 & 0 & 9 & 100 \\
\hline & Overall Percentage & 34.2 & 21.9 & 30.1 & 13.7 & 95.9 \\
\hline \multirow[t]{5}{*}{ Test } & normal & 17 & 0 & 0 & 0 & 100 \\
\hline & milder fibrosis & 0 & 6 & 0 & 0 & 100 \\
\hline & significant fibrosis & 0 & 2 & 8 & 1 & 72.7 \\
\hline & early cirrhosis & 0 & 0 & 0 & 3 & 100 \\
\hline & Overall Percentage & 45.9 & 21.6 & 21.6 & 10.8 & 91.9 \\
\hline
\end{tabular}


cellular oxidative stress [43]. In our research, Prx II has shown a significant up-regulation at the milder stage fibrosis, which indicated that it is an early protein target of HBV induced oxidative injury. On the contrary, current available fibrosis biomarkers, such as HA, CIV, PIIIP and LN, rely on the measurement of substances that participate in the generation of the liver extra cellular matrix and thus have limited clinical application value in milder fibrosis prediction.

As the complexity of liver fibrosis disallows any single biomarker to guide the diagnosis, prognosis, and treatment of the disease, we tried to use the tree classification system to predict the various fibrosis stages. Among the 25 serological analysis markers screened, PT, Pre, Prx II and HA were selected to construct a decision tree. The correct prediction percentages in both the training group and the test group were high. In the algorithm, Pre-albumin was used to correctly classify between normal and milder fibrosis, indicating an acute phase reaction at the beginning of fibrosis. Prx II was used to correctly classify between milder and significant fibrosis, indicating an anti-oxidative stress reaction during the progress of fibrosis. HA was used to correctly classify between significant fibrosis and early cirrhosis, indicating an assembling of ECM at the late stage of fibrosis.

\section{Conclusion}

In this study, we have shown the quantitative plasma protein profiles in various stages liver fibrosis patients, and have found several proteins that changed significantly during disease progression. The differential expressed proteins have four groups of biological functions, which is helpful for revealing the underlying mechanisms of liver fibrosis. The significant up-regulation of Prx II implied that it held comparable sensitivity and specificity in the prediction of milder fibrosis, which may be useful for early fibrosis diagnosis if validated in other cohorts.

\section{Additional material}

Additional file 1: Experiment design of DIGE. Additional file 1 contains Table S1, in which the experiment design of DIGE is explained and Figure S1, in which DIGE image of sample G3S1 labeled with Cy3 and $\mathrm{Cy} 5$ is shown. It can be seen that the spot pattern is reproducible with both dyes. Therefore, each sample was labeled with either $\mathrm{Cy} 3$ or Cy 5 and ran on two individual gels to eliminate the possible effect of different Dyes on sample electrophoresis.

Additional file 2: Identification of Prx II by MALDI-TOF MS/MS

Additional file 2 contains Figure $S 2$, in which MALDI-TOF MS map of Prx II, tandem MS/MS spectra of peptide m/z 1211.71, 1735.02 and 1864.11, and the amino acid sequences of Prx $\|$ are shown.

Additional file 3: Effect of albumin and IgG depletion. Additional file 3 contains Figure $\mathrm{S} 3$, in which 2-DE gels of raw plasma and depleted plasma are shown. It can be seen that after depletion, two most abundant plasma proteins, albumin and lgG, are successfully removed.

\section{Abbreviations}

HBV: hepatitis B virus; HCC: hepatocellular carcinoma; 2-DE: two-dimensional electrophoresis; 2-D DIGE: two-dimensional differential in-gel electrophoresis; ELISA: enzyme linked immunosorbent assay; ANOVA: analysis of variance; ROC: receiver operating characteristic; AUC: area under curve; Prx II: thioredoxin peroxidase; CLU: clusterin; LRG: leucine-rich alpha-2-glycoprotein; HA: hyaluronic acid; CIV: type IV collagen; PIIIP: N-terminal propeptide of type III procollagen; HP: haptoglobin; LN: laminin; Apo Al: apolipoprotein Al; ECM: extra cellular matrix; TNF-a: tumour necrosis factor alpha; PDGF: platelet-derived growth factor.

\section{Acknowledgements}

We thank Dr. Qingyi Wei and Dr. Wei Sun for advice and editorial comments. Financial supports are from National Natural Science Foundation of China (Nos.20627003, 30900257), Shanghai Science \& Technology Developing Program (No. 03DZ14024), the National Basic Research Program of China (No. 2006CB910803), the State Key Laboratory of Proteomics (No. SKLP-K200808), Chinese State Key Project Specialized for Infectious Diseases (No. 2008ZX10002-016, 2008ZX10002-019) and the Natural Science Foundation of Shanghai, China (No. 09ZR1404100).

\section{Author details}

${ }^{1}$ Department of Chemistry, Fudan University, Shanghai, China. ${ }^{2}$ Laboratory of Systems Biology, Institutes of Biomedical Sciences, Fudan University, Shanghai, China. ${ }^{3}$ Department of Molecular Biology for Public Health, Shanghai Municipal Centers for Disease Control and Prevention, Shanghai, China. ${ }^{4}$ Department of Gastroenterology, Zhongshan Hospital, Fudan University, Shanghai, China. ${ }^{5}$ State Key Laboratory of Proteomics, Beijing Proteome Research Center, Beijing Institute of Radiation Medicine, Beijing, China.

\section{Authors' contributions}

YL carried out the 2D-DIGE experiments, protein identification, participated in the data analysis and drafted the manuscript. JL carried out the serological analysis and participated in the statistical analysis. CL carried out the western blot analysis and participated in the data analysis. HW and YJ participated in the design of the study and performed the statistical analysis. JW, PY and FH conceived of the study, participated in its design and coordination and helped to draft the manuscript. All authors read and approved the final manuscript.

\section{Competing interests}

The authors declare that they have no competing interests.

Received: 21 August 2009 Accepted: 13 October 2010

Published: 13 October 2010

\section{References}

1. Oberti F, Valsesia E, Pilette C, Rousselet MC, Bedossa P, Aube C, Gallois Y, Rifflet $\mathrm{H}$, Maiga MY, Penneau-Fontbonne D, Cales P: Noninvasive diagnosis of hepatic fibrosis or cirrhosis. Gastroenterology 1997, 113:1609-1616.

2. Wai CT, Greenson JK, Fontana RJ, Kalbfleisch JD, Marrero JA, Conjeevaram HS, Lok AS-F: A simple noninvasive index can predict both significant fibrosis and cirrhosis in patients with chronic hepatitis $C$. Hepatology 2003, 38:518-526.

3. Guéchot J, Poupon RE, Giral P, Balkau B, Giboudeau J, Poupon R: Relationship between procollagen III amino terminal propeptide and hyaluronan serum levels and histological fibrosis in primary biliary cirrhosis and chronic viral hepatitis C. J Hepatol 1994, 20:388-393.

4. dos Santos VN, Leite-Mór MMB, Kondo M, Martins JR, Nader H, Lanzoni VP, Parise ER: Serum laminin, type IV collagen and hyaluronan as fibrosis markers in non-alcoholic fatty liver disease. Braz J Med Biol Res 2005, 38:747-753. 
5. Guechot J, Laudat A, Loria A, Serfaty L, Poupon R, Giboudeau J: Diagnostic accuracy of hyaluronan and type III procollagen amino- terminal peptide serum assays as markers of liver fibrosis in chronic viral hepatitis $C$ evaluated by ROC curve analysis. Clin Chem 1996, 42:558-563.

6. El-Gindy I, El Rahman AT, El-Alim MA, Zaki SS: Diagnostic potential of serum matrix metalloproteinase- 2 and tissue inhibitor of metalloproteinase-1 as non-invasive markers of hepatic fibrosis in patients with HCV related chronic liver disease. Egypt J Immunol 2003 10:27-35.

7. Wang H, Mengsteab S, Tag CG, Gao CF, Hellerbrand C, Lammert F, Gressner AM, Weiskirchen R: Transforming growth factor- $\beta 1$ gene polymorphisms are associated with progression of liver fibrosis in Caucasians with chronic hepatitis C infection. World J Gastroenterol 2005 11:1929-1936.

8. Kim J, Kim SH, Lee SU, Ha GH, Kang DG, Ha NY, Ahn JS, Cho HY, Kang SJ, Lee YJ, Hong SC, Ha WS, Bae JM, Lee CW, Kim JW: Proteome analysis of human liver tumor tissue by two-dimensional gel electrophoresis and matrixassisted laser desorption/ionization-mass spectrometry for identification of disease-related proteins. Electrophoresis 2002, 23:4142-4156.

9. Chen G, Gharib TG, Huang CC, Thomas DG, Shedden KA, Taylor JM, Kardia SL, Misek DE, Giordano TJ, lannettoni MD, Orringer MB, Hanash SM, Beer DG: Proteomic Analysis of Lung Adenocarcinoma: Identification of a Highly Expressed Set of Proteins in Tumors. Clin Cancer Res 2002, 8:2298-2305

10. Meehan $\mathrm{KL}$, Holland JW, Dawkins HJ: Proteomic analysis of normal and malignant prostate tissue to identify novel proteins lost in cancer. Prostate 2002, 50:54-63.

11. Wulfkuhle JD, Sgroi DC, Krutzsch H, McLean K, McGarvey K, Knowlton M, Chen S, Shu H, Sahin A, Kurek R, Wallwiener D, Merino MJ, Petricoin EF III, Zhao YM, Steeg PS: Proteomics of Human Breast Ductal Carcinoma in Situ. Cancer Res 2002, 62:6740-6749.

12. Klade CS, Voss T, Krystek E, Ahorn H, Zatloukal H, Pummer K, Adolf GR: Identification of tumor antigens in renal cell carcinoma by serological proteome analysis. Proteomics 2001, 1:890-898.

13. He QY, Chen J, Kung HF, Yuen APW, Chiu JF: Identification of tumorassociated proteins in oral tongue squamous cell carcinoma by proteomics. Proteomics 2004, 4:271-278.

14. Chen J, He QY, Yuen AP, Chiu JF: Proteomics of buccal squamous cell carcinoma: The involvement of multiple pathways in tumorigenesis. Proteomics 2004, 4:2465-2475.

15. Zhang LY, Ying WT, Mao TS, He HZ, Liu Y, Wang HX, Liu F, Wang $K$, Zhang DC, Wang Y, Wu M, Qian XH, Zhao XH: Loss of clusterin both in serum and tissue correlates with the tumorigenesis of esophageal squamous cell carcinoma via proteomics approaches. World J Gastroenterol 2003, 4:650-654.

16. Moreira JM, Gromov P, Celis JE: Expression of the tumor suppressor protein $14-3-3 \sigma$ is down regulated in invasive transitional cell carcinoma of the urinary bladder undergoing epithelial mesenchymal transition. Mol Cell Proteomics 2004, 3:410-419.

17. Srisomsap C, Sawangareetrakul $P$, Subhasitanont $P$, Panichakul $T$, Keeratichamroen S, Lirdprapamongkol K, Chokchaichamnankit D, Sirisinha S, Svasti J: Proteomic analysis of cholangiocarcinoma cell line. Proteomics 2004, 4:1135-1144.

18. O'Farrell PH: High resolution two-dimensional electrophoresis of proteins. J Biol Chem 1975, 250:4007-4021.

19. Unlu M, Morgan ME, Minden JS: Two-Dimensional Electrophoresis Difference gel electrophoresis. A single gel method for detecting changes in protein extracts. Electrophoresis 1997, 18:2071-2077.

20. Wayne FP: Detection technologies in proteome analysis. $J$ of Chromatography B 2002, 771:3-31.

21. Willard MF, Scott EH: Proteomics for protein expression profiling in neuroscience. Neurochemical Research 2004, 29:1065-1081.

22. Desmet VJ, Gerber M, Hoofnagle JH, Manns M, Scheuer P: Classification of Chronic Hepatitis: Diagnosis, Grading and Staging. J Hepatology 1994, 19:1513-1520.

23. Lv S, Wei L, Wang JH, Wang JY, Liu F: Identification of Novel Molecular Candidates for Acute Liver Failure in Plasma of BALB/c Murine Model. $J$ Proteome Res 2007, 6(7):2746-2752.

24. Anderson NL, Anderson NG: The Human Plasma Proteome: History, Character, and Diagnostic Prospects. Mol Cell Proteomics 2002, 1:845-867.
25. Xu A, Wang Y, Xu JY, Stejskal D, Tam S, Zhang J, Wat NM, Wong WK, Lam KS: Adipocyte Fatty Acid-Binding Protein Is a Plasma Biomarker Closely Associated with Obesity and Metabolic Syndrome. Clin Chem 2006, 52(3):405-413.

26. Schorge JO, Drake RD, Lee H, Skates SJ, Rajanbabu R, Miller DS, Kim JH, Cramer DW, Berkowitz RS, Mok SC: Osteopontin as an Adjunct to CA125 in Detecting Recurrent Ovarian Cancer. Clin Cancer Res 2004, 10(10):3474-3478.

27. Putnam RW: the Plasma Proteins. Academic Press, New York 1975, 23-34

28. Tang HY, Ali-Khan N, Echan LA, Levenkova N, Rux JJ, Speicher DW: A novel four-dimensional strategy combining protein and peptide separation methods enables detection of low-abundance proteins in human plasma and serum proteomes. Proteomics 2005, 5:3329-3342.

29. Echan LA, Tang HY, Ali-Khan N, Lee K, Speicher DW: Depletion of multiple high-abundance proteins improves protein profiling capacities of human serum and plasma. Proteomics 2005, 5:3292-3303.

30. Kendziorski C, Irizarry RA, Chen KS, Haag JD, Gould MN: On the utility of pooling biological samples in microarray experiments. Proc Natl Acad Sci USA 2005, 102:4252-4257.

31. Kendziorski CM, Zhang Y, Lan H, Attie AD: The efficiency of pooling mRNA in microarray experiments. Biostatistics 2003, 4:465-477.

32. Peng $X$, Wood CL, Blalock EM, Chen KC, Landfield PW, Stromberg AJ: Statistical implications of pooling NA samples for microarray experiments. BMC Bioinformatics 2003, 4:26.

33. Arthur MJ: Degradation of matrix proteins in liver fibrosis. Pathology research and practice 1994, 190:825-833.

34. Li X, Miyajima M, Mineki R, Taka H, Murayama K, Arai H: Analysis of potential diagnostic biomarkers in cerebrospinal fluid of idiopathic normal pressure hydrocephalus by proteomics. Acta Neurochir (Wien) 2006, 148:859-864

35. Janig E, Stumptner C, Fuchsbichler A, Denk H, Zatloukal K: Interaction of stress proteins with misfolded keratins. Eur J Cell Biol 2005, 84:329-39.

36. Chae HZ, Robison K, Poole LB, Church G, Storz G, Rhee SG: Cloning and sequencing of thiol-specific antioxidant from mammalian brain: alkyl hydroperoxide reductase and thiol-specific antioxidant define a large family of antioxidant enzymes. Proc Natl Acad Sci USA 1994, 91:7017-7021.

37. Hofmann B, Hecht HJ, Flohe L: Peroxideroxins. Biol Chem 2002, 383:347-364.

38. Shimizu I: Recent Therapeutic Developments in Hepatic Fibrosis. Current Drug Targets Infectious Disorders 2001, 1:227-240.

39. Shimizu I: Impact of oestrogens on the progression of liver disease. Liver International 2003, 23:63-69.

40. Kim BJ, Hood BL, Aragon RA, Hardwick JP, Conrads TP, Veenstra TD, Song BJ: Increased oxidation and degradation of cytosolic proteins in alcohol-exposed mouse liver and hepatoma cells. Proteomics 2006 , 6:1250-1260

41. Meneses-Lorente G, Guest PC, Lawrence J, Muniappa N, Knowles MR, Skynner HA, Salim K, Cristea I, Mortishire-Smith R, Gaskell SJ, Watt A: A Proteomic Investigation of Drug-Induced Steatosis in Rat Liver. Chem Res Toxicol 2004, 17:605-612.

42. Heijne $W H$, Slitt AL, van Bladeren PJ, Groten JP, Klaassen CD, Stierum RH, van Ommen B: Bromobenzene-Induced Hepatotoxicity at the Transcriptome Level. Toxicol Sci 2004, 79:411-422.

43. Zhang $W$, Wang $M$, Xie HY, Zhou L, Meng XQ, Shi J, Zheng S: Role of Reactive Oxygen Species in Mediating Hepatic Ischemia-Reperfusion Injury and Its Therapeutic Applications in Liver Transplantation. Transplant Proc 2007, 39:1332-1337.

\section{Pre-publication history}

The pre-publication history for this paper can be accessed here: http://www.biomedcentral.com/1471-230X/10/115/prepub

doi:10.1186/1471-230X-10-115

Cite this article as: Lu et al.: Peroxiredoxin 2: a potential biomarker for early diagnosis of Hepatitis B Virus related liver fibrosis identified by proteomic analysis of the plasma. BMC Gastroenterology 2010 10:115. 